\title{
Expression of Phospholipase A2 Receptor in Pediatric Hepatitis B Virus-Related Membranous Nephropathy
}

\author{
Sung-Eun Choi, M.D. ${ }^{1}$ \\ Yoon Sung Bae, M.D. ${ }^{1}$ \\ Keum Hwa Lee, M.D., Ph.D. ${ }^{2}$ \\ Jae Il Shin, M.D., Ph.D. ${ }^{2}$ \\ Hyeon Joo Jeong, M.D., Ph.D.' \\ Beom Jin Lim, M.D., Ph.D. ${ }^{1}$ \\ Department of Pathology ${ }^{1}$, Yonsei \\ University College of Medicine, Seoul, \\ Korea, Department of Pediatrics', \\ Yonsei University College of Medicine, \\ Seoul, Korea

\section{Corresponding author:} \\ Beom Jin Lim, M.D., PhD. \\ Department of Pathology, Yonsei \\ University College of Medicine, Gangnam \\ Severance Hostpital, 211, Eonju-ro, \\ Gangnam-gu, Seoul, 06273, Korea \\ Tel: $+82-2-2019-3540$ \\ Fax: +82-2-3463-2103 \\ E-mail: bjlim@yuhs.ac
}

Received: 28 February 2020

Revised: 19 March 2020

Accepted: 9 April 2020
Purpose: Hepatitis B virus (HBV) infection is among etiologies of secondary membranous nephropathy (MN) in pediatric patients. We evaluated expression of phospholipase $\mathrm{A} 2$ receptor (PLA2R), a specific target antigen of primary $M N$, in pediatric HBV-related MN.

Methods: We retrospectively reviewed patients with biopsy-proven HBV-related MN from the renal biopsy registry and electronic medical records of Severance Hospital, Seoul, Korea, from 1993 to 2004. Paraffin-embedded human kidney tissues were retrieved and immunohistochemically stained for PLA2R.

Results: Ten pediatric patients with 13 biopsied specimens were reviewed. The predominant pathological stage was stage II-III, and second was stage II. The intensity of staining for $\lg G$ was greatest, with less intense staining for $\lg M$, $\lg A$, $\mathrm{C} 3, \mathrm{C} 4$, and $\mathrm{C} 1 \mathrm{q}$. All the patients had angiotensin-converting enzyme inhibitor combined with glucocorticoid, and four patients converted to cyclosporine treatment from glucocorticoid monotherapy. Urinalysis of all the patients normalized after variable period. PLA2R staining was demonstrated in the outer glomerulus in 3 out of 13 biopsies, 2 of which were obtained from the same patient over a 5 -year interval.

Conclusions: PLA2R was expressed in a small number of cases diagnosed as pediatric $\mathrm{HBV}$-related $\mathrm{MN}$, indicating that some HBV-related $\mathrm{MN}$ cases may be primary $\mathrm{MN}$ concurrent with $\mathrm{HBV}$ infection.

Key words: Membranous glomerulonephritis, Phospholipase A2 receptor, Hepatitis B, Childhood

\section{Introduction}

Membranous nephropathy (MN) is a pathological entity defined by the presence of subepithelial immune deposits that induce a spectrum of changes in the glomerular basement membrane. $\mathrm{MN}$ can be divided into primary and secondary forms. The majority of primary $\mathrm{MN}$ cases are understood to be mediated by an autoantibody to phospholipase A2 receptor (PLA2R) expressed on podocytes ${ }^{1)}$. MN may also occur secondary to other conditions, with infection as one etiology. In contrast to primary $\mathrm{MN}$, the immune complex of secondary MN is likely to derive from non-glomerular antigen from the specific etiologic agent. MN arising in the background of hepatitis B virus (HBV) infection has been understood as secondary MN. In children, primary $\mathrm{MN}$ is a much less common etiology of nephrotic syndrome ${ }^{2}$, and secondary forms

\footnotetext{
This is an open-access article distributed under the terms of the Creative Commons Attribution Non-Commercial License (http:// which permits unrestricted non-commercia use, distribution, and reproduction in an medium, provided the original work is properly cited.
}

Pediatric Nephrology 
of $\mathrm{MN}$ are more common ${ }^{3)}$. Although the pathogenesis is shared in primary $\mathrm{MN}$ and secondary $\mathrm{MN}$ associated with $\mathrm{HBV}$, the clinical course and treatment is quite different. As approximately one third of primary MN spontaneously resolve at 10 years follow up ${ }^{4)}$, HBV-MN in children resolves spontaneously in many cases, in association with seroconversion of hepatitis B e-antigen ( $\mathrm{HBeAg})^{5)}$. The treatment of primary $\mathrm{MN}$ is either conservative therapy, or immunosuppressive treatment, which is considered for those in risk of progression, after assessment of several pathologic and clinical prognostic factors ${ }^{6}$. Antiviral therapy is usually sufficient for most of the HBV-MN cases $^{7}$. However, the association between primary MN and HBV-MN has not been well-investigated. Because data on PLA2R expression in HBV-related MN have been lacking, the true incidences of primary and secondary $\mathrm{MN}$ in $\mathrm{HBV}$ infection are not yet known, as well. Therefore, we evaluated PLA2R expression in biopsy-proven $\mathrm{MN}$ cases associated with HBV.

\section{Materials and methods}

\section{Case retrieval and clinicopathological review}

We retrieved 10 childhood patients with biopsy-proven HBV-related MN from the renal biopsy registry and electronic medical records of Severance Hospital, Seoul, Korea, from the years 1993 to 2004. Clinical history and histological data were collected by reviewing electronic medical records.

\section{Immunohistochemical staining of PLA2R}

Paraffin-embedded human kidney tissues from 10 patients were obtained from the surgical pathology archive of the Department of Pathology, Yonsei University, Severance Hospital (Seoul, South Korea). Paraffin-embedded samples were cut into $4-\mu \mathrm{m}$ sections, deparaffinized, and rehydrated with a graded series of alcohol and water. Heat-induced antigen retrieval was performed in Bond Epitope Retrieval Solution 2 (Leica Microsystems, Ltd., Wetzlar, Germany) at $98^{\circ} \mathrm{C}$ for 20 minutes. Kidney tissues were stained using the Bond-III automated staining platform (Leica Microsystems, Ltd.). Endogenous peroxidase activity was blocked by incubation with $0.3 \%$ hydrogen peroxide for 10 minutes. The tissue sections were then incubated overnight with a primary antibody against PLA2R (dilution 1:2,000; SigmaAldrich, St. Louis, MO, USA) at $4^{\circ} \mathrm{C}$, followed by incubation with Bond Polymer Refine Detection reagent (Leica). This study was approved by the Institutional Review Board of Severance Hospital (4-2014-0828).

\section{Results}

The retrieved cases included 13 biopsies from 10 patients. Baseline patient demography is shown in Table 1 . The median age was 9.54 years (range 3-15). A total of 10 biopsies (76.9\%) were from males and 3 biopsies were from females (23.1\%). Stage II-III was the predominant pathological stage, representing $46.2 \%$ of cases, with stage II as the second most predominant (38.5\%). The median number of glomeruli per biopsied tissue was 41.6 (range 14-139). The intensity of immunofluorescent staining for IgG was $2+$ or $3+$ in 11 cases (84.6\%), whereas staining intensities for IgA, C4, and $\mathrm{Clq}$ were no more than 1+. Pathologic findings in favor of secondary HBV-related MN such as mesangial hypercellularity, mesangial widening, and electron-dense deposits in mesangium were noted in four patients, and all of them were PLA2R-negative. All the patients started treatment at a similar point when they were pathologically diagnosed as membranous nephropathy. The treatment was conservative agent such as angiotensin-converting enzyme inhibitor and glucocorticoid. Four patients who did not respond well to glucocorticoid or had much severe symptoms such as nephrotic syndrome, received more aggressive immunosuppressive agents like cyclosporine A. Two out of the 4 patients had interferon-alpha following cyclosporine A, which was used for a treatment of active B-viral hepatitis. After a period ranging from 3 months to 22 months, all the patients were free of proteinuria and hematuria with seroconversion of $\mathrm{HBeAg}$ to anti-hepatitis B e-antibody (anti-HBe-Ab). Three cases stained positive for PLA2R along the outer surface glomerular capillary walls (Fig. 1); two of these cases were biopsied from the same patient over a 5-year interval. Patient demographics, pathological findings, immunofluorescence findings, electron microscopy findings, and treatment were comparatively analyzed in between PLA2R negative and positive groups, but no statistically significant results were obtained. Immunohisto- 
chemistry for hepatitis B core antigen (HBcAg) had been performed at the time of biopsy in some cases, with negative results.

\section{Discussion}

After the development of the Heymann nephritis model, MN has been understood to be caused by autosensitization
${ }^{8)}$. Although megalin was soon identified as a target antigen in rat ${ }^{9}$, PLA2R was only recently identified as a target antigen in humans ${ }^{1)}$. During the decade since that discovery, much has been learned about the biological nature and clinical significance of PLA2R in the diagnosis and treatment of $\mathrm{MN}^{10)}$. PLA2R is a transmembrane receptor of mannose receptor family that constitutively undergo endocytosis. Thus, on PLA2R immunohistochemical stain, it appears as weak background staining on the cytoplasm

Table 1. Patient Demography with Immunopathological Features, Treatment and Outcome

\begin{tabular}{|c|c|c|c|c|c|c|c|c|c|c|c|c|c|c|c|c|}
\hline No. & $\begin{array}{c}\text { Age } \\
\text { (Years) }\end{array}$ & Sex & Stage & $\begin{array}{c}\text { Number of } \\
\text { glomeruli }\end{array}$ & $\lg A$ & $\lg G$ & $\lg M$ & C3 & C4 & $\mathrm{Clq}$ & PLA2R & $\begin{array}{l}\text { Additional } \\
\text { Finding* }\end{array}$ & $E M^{* *}$ & $\begin{array}{c}\text { Treatment } \\
\text { (month) }\end{array}$ & $\begin{array}{l}\text { Outcome }^{\dagger} \\
\text { (month) }\end{array}$ & Seroconversion $^{\ddagger}$ \\
\hline 1 & 9 & $M$ & $|-|||$ & 61 & - & ++ & - & - & - & - & - & $\begin{array}{l}\text { Mesangial } \\
\text { expansion with } \\
\text { hypercellularity } \\
\text { Cannot exclude } \\
\text { CsA toxicity }\end{array}$ & $\begin{array}{l}\text { Subepithelial and } \\
\text { some minute } \\
\text { subendothelial, } \\
\text { intramembranous, } \\
\text { mesangial EDD }\end{array}$ & $\begin{array}{l}\text { Cyclosporine A } \\
\text { (8) and alpha- } \\
\text { interferon (15) }\end{array}$ & UA normal (3) & After 4 years \\
\hline 2 & 11 & M & $\|-\| \|$ & 21 & - & ++ & + & + & - & - & - & $\begin{array}{l}\text { FSGS in } 1 \\
\text { glomerulus }\end{array}$ & $\begin{array}{l}\text { Subepithelial and } \\
\text { no mesangial EDD }\end{array}$ & Cyclosporine A (3) & UA normal (22) & After 5 years \\
\hline 2 & 13 & M & $\|-|| \mid$ & 14 & - & + & + & + & - & - & - & & - & $\begin{array}{l}\text { ACE inhibitor and } \\
\text { glucocorticoid }\end{array}$ & & \\
\hline 3 & 9 & $\mathrm{~F}$ & III & 28 & - & ++ & ++ & ++ & - & + & - & & - & $\begin{array}{c}\text { Cyclosporine A } \\
\text { (13) }\end{array}$ & & \\
\hline 3 & 10 & F & $\|$ & 36 & - & ++ & + & + & - & - & - & & - & & UA normal (4) & \\
\hline 4 & 13 & M & $\|$ & 15 & - & ++ & - & - & - & + & + & & - & $\begin{array}{l}\text { ACE inhibitor and } \\
\text { glucocorticoid }\end{array}$ & UA normal (29) & \\
\hline 5 & 7 & M & $\|-|| \mid$ & 62 & - & ++ & - & + & - & + & - & & $\begin{array}{c}\text { Subepithelial EDD } \\
\text { and mesangial slight } \\
\text { widening with some } \\
\text { EDD }\end{array}$ & $\begin{array}{l}\text { ACE inhibitor and } \\
\text { glucocorticoid }\end{array}$ & UA normal (1) & \\
\hline 6 & 5 & M & $\|-|\||$ & 139 & - & ++ & - & - & + & - & - & & - & $\begin{array}{l}\text { Cyclosporine A } \\
\text { (23) and alpha- } \\
\text { interferon (4-6) }\end{array}$ & $\begin{array}{c}\text { UA protein free } \\
\text { (13) }\end{array}$ & After 3 years \\
\hline 7 & 11 & F & I & 54 & + & ++ & + & + & + & - & - & & - & $\begin{array}{l}\text { ACE inhibitor and } \\
\text { glucocorticoid }\end{array}$ & $\begin{array}{l}\text { UA normal } \\
(22)\end{array}$ & After 1 year \\
\hline 8 & 10 & M & $\|$ & 31 & - & ++ & + & + & - & + & - & $\begin{array}{l}\text { Spotty lgM in } \\
\text { mesangium }\end{array}$ & - & $\begin{array}{c}\text { Alpha-interferon } \\
\text { (3) }\end{array}$ & $\begin{array}{c}\text { UA protein free } \\
\text { (6), relapse (13) } \\
\text { and UA normal } \\
\text { (24) }\end{array}$ & After 3 years \\
\hline 9 & 15 & M & $\|$ & 23 & - & ++ & - & - & - & + & - & $\begin{array}{c}\text { Minimal } \\
\text { segmental } \\
\text { mesangial } \\
\text { expansion } \\
\text { with increased } \\
\text { cellularity in } 3 \\
\text { glomeruli }\end{array}$ & - & $\begin{array}{l}\text { ACE inhibitor and } \\
\text { glucocorticoid }\end{array}$ & UA normal (6) & After 2 months \\
\hline 10 & 3 & M & $\|$ & 39 & - & +++ & - & ++ & - & - & + & & - & $\begin{array}{l}\text { ACE inhibitor and } \\
\text { glucocorticoid }\end{array}$ & $\begin{array}{l}\text { UA protein free } \\
\text { (1) follow-up } \\
\text { biopsy showed } \\
\text { remission (108) }\end{array}$ & After 3 years \\
\hline 10 & 8 & M & $\|-||$ & $17-19$ & - & + & - & - & - & - & + & & - & $\begin{array}{l}\text { ACE inhibitor and } \\
\text { glucocorticoid }\end{array}$ & & \\
\hline
\end{tabular}

Abbreviations: ACE, angiotensin-converting enzyme; EDD, electron-dense deposits; FSGS, focal segmental glomerulosclerosis; UA, urinalysis.

* and **. Histopathological findings in favor of secondary HBV-MN such as EDD are noted.

${ }^{\dagger} U A$ normal is defined as urine free of hemoglobin and protein. Number in parentheses is the period from first renal biopsy date to achieve normal UA.

${ }^{\ddagger}$ Period from first renal biopsy date to achieve seroconversion of anti-HBe-Ab is noted. IgA, lgG, IgM, C3, C4, and C1q as immunofluorescence results, and PLA2R as immunohistochemical stain results. 


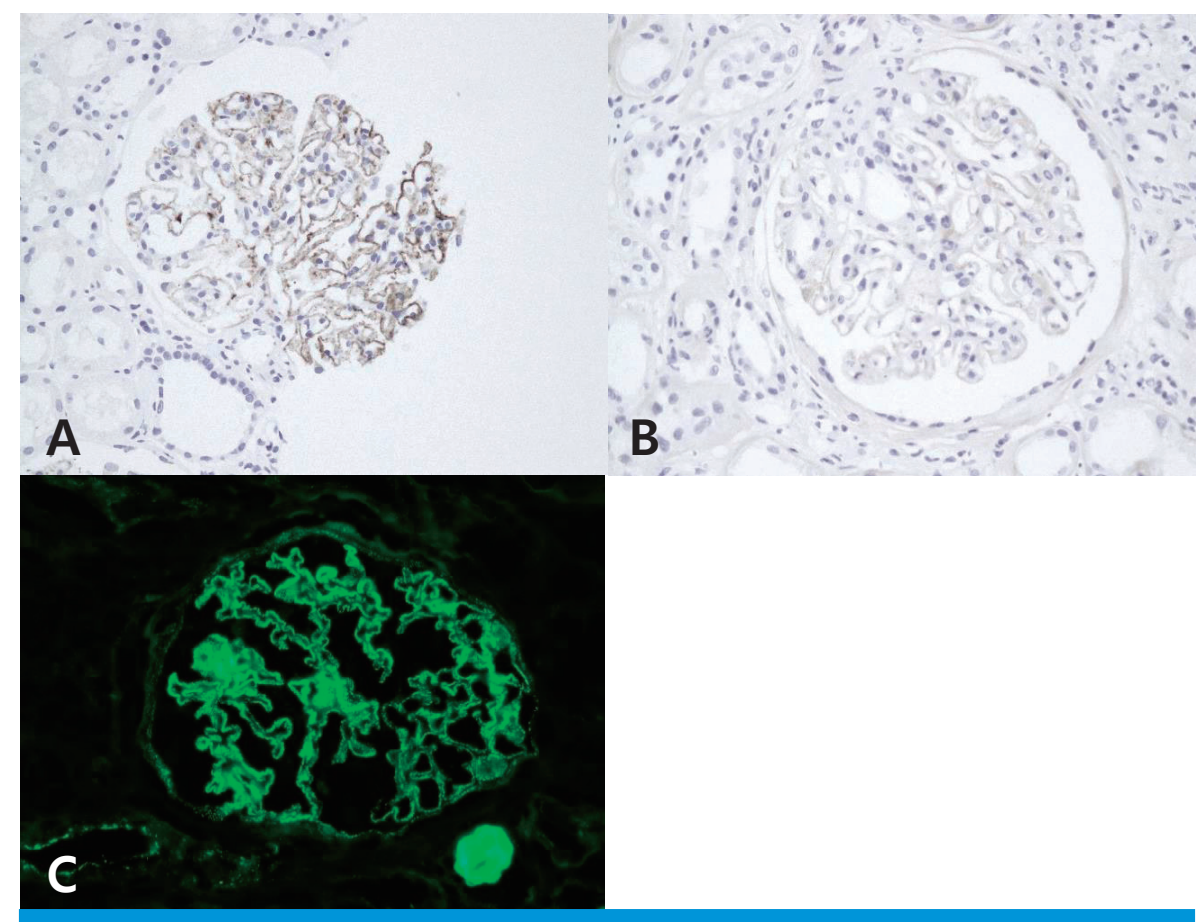

Fig. 1. Representative photos of positive (A) and negative (B) immunohistochemical staining for PLA2R, and granular immune deposits of IgG on immunofluorescent stain (C). As PLA2R stains strongly in subepithelial space (A), it stains weakly in cytoplasm of podocytes (B) which physiologically recycles from the plasma membrane and cytoplasm via endocytosis, which is a normal background finding. Both the PLA2R and IgG are stained granular along capillary loops, indicating the subepithelial presence of immune deposits containing PLA2R and lgG, respectively.

of podocytes. In contrast, PLA2R-positive $\mathrm{MN}$ shows strong PLA2R immunohistochemical positivity in subepithelial space, indicating the subepithelial presence of immunecomplex deposits including PLA2 $\mathrm{R}^{11}$. Glomerular subepithelial PLA2R expression has even become one of the essential diagnostic features of primary $\mathrm{MN}^{12}$. Secondary forms of MN are likely to involve immune responses to non-glomerular antigens, either those planted on the glomerular basement membrane and bound in situ by circulating antibodies or circulating antigens in the form of antigen-antibody complexes deposited in the subepithelial area. Etiologies for secondary MN include autoimmune rheumatologic disease, therapeutic agents such as gold or penicillamine, malignancy, and infection ${ }^{3)}$. In children, infection and autoimmune disease are the most common causes of secondary $\mathrm{MN}^{13}$.

HBV-related $\mathrm{MN}$ is a well-known example of secondary MN. Its incidence is thought to be higher among pediatric patients than in adult HBV-infected patients ${ }^{14-16)}$. Most children infected with HBV will become chronic carriers ${ }^{14)}$, while the majority of adults seroconvert, with disappearance of hepatitis B surface antigen (HBsAg), $\mathrm{HBeAg}$, and $\mathrm{HBV}$ $\mathrm{DNA}^{15)}$. HBeAg has been demonstrated within glomerular immune deposits of HBV-related $\mathrm{MN}^{5,17)}$ and $\mathrm{HBcAg}$ has also demonstrated in glomerular deposits of two-thirds of the children infected with $\mathrm{HBV}^{18}$. Unfortunately, our data regarding $\mathrm{HBcAg}$ expression did not aid in distinguishing between primary and secondary $\mathrm{MN}$.

Histologic features, such as mesangial/endocapillary hypercellularity or immune deposits in locations other than the subepithelial space, are more frequently observed in secondary $\mathrm{MN}^{19)}$, and some of our cases showed such findings. However, no single morphology is pathognomonic for distinguishing between primary and secondary MN. Although PLA2R is a reliable marker of primary MN, not every primary $M N$ is associated with PLA2R. PLA2R is identified in about $80 \%$ of primary $\mathrm{MN}^{20)}$, whereas thrombospondin type-1 domain-containing 7A (THSD7A) is detected in $10 \%$ of PLA2R-negative patients ${ }^{21)}$. In addition, it has been demonstrated that childhood primary $\mathrm{MN}$ showed weaker PLA2R staining than that observed in adult patients ${ }^{22}$. In our study, PLA2R was present in a small 
www.chikd.org

number of cases ( 2 out of 10 patients, and 3 out of 13 biopsies), meaning that some cases of $\mathrm{MN}$ in the background of HBV may not represent true secondary MN. Svobodova et al. also reported that two cases of HBV-related MN showed PLA2R positivity; however, they did not include PLA2R-negative cases among their study subjects ${ }^{23}$. Cases of hepatitis $\mathrm{C}$ virus-related $\mathrm{MN}$ showing PLA2R-positivity have been also reported ${ }^{24)}$. The prevalence of PLA2R-positivity in "secondary" forms of MN varies; several studies have shown low prevalence while one retrospective study has shown 64 percent of PLA2R-positivity in 39 cases of HBV-MN ${ }^{25}$. THSD7A has been demonstrated to provide causal relationship between gallbladder carcinoma and the development of $\mathrm{MN}^{26)}$. However, few studies have investigated the mechanism of PLA2R positivity in secondary $\mathrm{MN}$. Some suggest coincidence of PLA2R-positive primary $\mathrm{MN}$ with secondary $\mathrm{MN}^{27)}$, and others suggest the immunologic background of secondary disease such as sarcoidosis or hepatitis B might trigger immunization against $P L A 2 R^{28)}$. Therefore, it seems that discriminating primary and secondary MN based solely on PLA2R is inappropriate, and more study is needed to validate the association between PLA2R-positive MN and HBV-MN. As all the patients in our study achieved remission on urinalysis with seroconversion, HBV-related MN seems to be more likely on clinical context in spite of the PLA2R positivity.

Distinguishing primary from secondary $\mathrm{MN}$ in the background of HBV infection has clinical significance because anti-viral therapy may be effective in controlling secondary $\mathrm{MN}^{29)}$. The limitation of our study is that it is retrospective, which made use of archival paraffin-embedded tissues. Because the incidence of childhood HBVrelated MN has decreased markedly in recent years, all the cases included were collected during the 1990s and early 2000s. Lack of clinical data limited multifactorial analysis. Tests for THSD7A or IgG subtype analyses (to verify IgG4 dominancy in primary $\mathrm{MN}$ ) were not performed because the amount of tissue was insufficient.

Conclusion: Some HBV-related MN in children showed glomerular PLA2R expression. In these cases the possibility of primary MN superimposed on $\mathrm{HBV}$ infection cannot be ruled out.

\section{Acknowledgement}

This study was supported by a faculty research grant of Yonsei University College of Medicine (6-2014-0190).

\section{ORCID}

Sung-Eun Choi. https://orcid.org/0000-0002-6955-658X Yoon Sung Bae.

Keum Hwa Lee. http://orcid.org/0000-0002-1511-9587

Jae Il Shin. http://orcid.org/0000-0003-2326-1820

Hyeon Joo Jeong. http://orcid.org/0000-0002-9695-1227

Beom Jin Lim. http://orcid.org/0000-0003-2856-0133

\section{Conflicts of interest}

No potential conflict of interest relevant to this article was reported.

\section{References}

1. Beck LH, Jr., Bonegio RG, Lambeau G, Beck DM, Powell DW, Cummins TD, et al. M-type phospholipase A2 receptor as target antigen in idiopathic membranous nephropathy. N Engl J Med 2009;361:11-21

2. Chen A, Frank R, Vento S, Crosby V, Chandra M, Gauthier B, et al. Idiopathic membranous nephropathy in pediatric patients: presentation, response to therapy, and long-term outcome. BMC Nephrol 2007;8:11.

3. Glassock RJ. Secondary membranous glomerulonephritis. Nephrol Dial Transplant 1992;7 Suppl 1:64-71.

4. Cattran DC. Membranous nephropathy: quo vadis? Kidney Int 2002:61:349-50

5. Takekoshi Y, Tochimaru H, Nagata Y, Itami N. Immunopathogenetic mechanisms of hepatitis B virus-related glomerulopathy. Kidney Int Suppl 1991;35:S34-9.

6. De Vriese AS, Glassock RJ, Nath KA, Sethi S, Fervenza FC. A Proposal for a Serology-Based Approach to Membranous Nephropathy. J Am Soc Nephrol 2017;28:421-30.

7. Kupin WL. Viral-Associated GN: Hepatitis B and Other Viral Infections. Clin J Am Soc Nephrol 2017;12:1529-33.

8. Heymann W, Hackel DB, Harwood S, Wilson SG, Hunter JL. Production of nephrotic syndrome in rats by Freund's adjuvants and rat kidney suspensions. Proc Soc Exp Biol Med 1959;100:660-4. 
9. Kerjaschki D, Farquhar MG. The pathogenic antigen of Heymann nephritis is a membrane glycoprotein of the renal proximal tubule brush border. Proc Natl Acad Sci U S A 1982;79:5557-61.

10. van de Logt AE, Fresquet M, Wetzels JF, Brenchley P. The antiPLA2R antibody in membranous nephropathy: what we know and what remains a decade after its discovery. Kidney Int 2019; 96:1292-302.

11. VanBeek C, Haas M. Anti-PLA2R-associated membranous nephropathy: a review with emphasis on diagnostic testing methods. Clin Nephrol 2015;84:1-9.

12. Debiec H, Ronco P. PLA2R autoantibodies and PLA2R glomerular deposits in membranous nephropathy. N Engl J Med 2011;364: 689-90.

13. Kleinknecht C, Levy M, Gagnadoux MF, Habib R. Membranous glomerulonephritis with extra-renal disorders in children. Medicine (Baltimore) 1979;58:219-28.

14. Johnson RJ, Couser WG. Hepatitis B infection and renal disease: clinical, immunopathogenetic and therapeutic considerations. Kidney Int 1990;37:663-76.

15. Bhimma R, Coovadia HM. Hepatitis B virus-associated nephropathy. Am J Nephrol 2004;24:198-211.

16. Gilbert RD, Wiggelinkhuizen J. The clinical course of hepatitis B virus-associated nephropathy. Pediatr Nephrol 1994;8:11-4.

17. Lai KN, Lai FM, Tam JS. Comparison of polyclonal and monoclonal antibodies in determination of glomerular deposits of hepatitis $B$ virus antigens in hepatitis B virus-associated glomerulonephritides. Am J Clin Pathol 1989;92:159-65.

18. Slusarczyk J, Michalak T, Nazarewicz-de Mezer T, Krawczynski K, Nowoslawski A. Membranous glomerulopathy associated with hepatitis B core antigen immune complexes in children. Am J Pathol 1980;98:29-43.

19. Lai FM, To KF, Wang AY, Choi PC, Szeto CC, Li PK, et al. Hepatitis B virus-related nephropathy and lupus nephritis: morphologic similarities of two clinical entities. Mod Pathol 2000;13:166-72.
20. Du Y, Li J, He F, Lv Y, Liu W, Wu P, et al. The diagnosis accuracy of PLA2R-AB in the diagnosis of idiopathic membranous nephropathy: a meta-analysis. PLoS One 2014;9:e104936.

21. Ren S, Wu C, Zhang Y, Wang AY, Li G, Wang L, et al. An update on clinical significance of use of THSD7A in diagnosing idiopathic membranous nephropathy: a systematic review and metaanalysis of THSD7A in IMN. Ren Fail 2018;40:306-13.

22. Kanda S, Horita S, Yanagihara T, Shimizu A, Hattori M. M-type phospholipase A2 receptor (PLA2R) glomerular staining in pediatric idiopathic membranous nephropathy. Pediatr Nephrol 2017;32:713-7.

23. Svobodova B, Honsova E, Ronco P, Tesar V, Debiec H. Kidney biopsy is a sensitive tool for retrospective diagnosis of PLA2Rrelated membranous nephropathy. Nephrol Dial Transplant 2013;28:1839-44.

24. Larsen CP, Messias NC, Silva FG, Messias E, Walker PD. Determination of primary versus secondary membranous glomerulopathy utilizing phospholipase $\mathrm{A} 2$ receptor staining in renal biopsies. Mod Pathol 2013;26:709-15.

25. Xie Q, Li Y, Xue J, Xiong Z, Wang L, Sun Z, et al. Renal phospholipase $A 2$ receptor in hepatitis $B$ virus-associated membranous nephropathy. Am J Nephrol 2015;41:345-53.

26. Hoxha E, Wiech T, Stahl PR, Zahner G, Tomas NM, Meyer-Schwesinger C, et al. A Mechanism for Cancer-Associated Membranous Nephropathy. N Engl J Med 2016;374:1995-6.

27. Qin W, Beck LH, Jr., Zeng C, Chen Z, Li S, Zuo K, et al. Anti-phospholipase $A 2$ receptor antibody in membranous nephropathy. J Am Soc Nephrol 2011;22:1137-43.

28. Debiec H, Ronco P. Immunopathogenesis of membranous nephropathy: an update. Semin Immunopathol 2014;36:381-97.

29. Sun IO, Hong YA, Park HS, Choi SR, Chung BH, Park CW, et al. Experience of anti-viral therapy in hepatitis B-associated membranous nephropathy, including Lamivudine-resistant strains. Korean J Intern Med 2012;27:411-6. 